Article

\title{
Guilt and the Consumption of Products with an Unhealthy Image
}

\author{
Jaeho Yang ${ }^{1}$ and Bokyeong Kim ${ }^{2, *}$ (D) \\ 1 Department of Business Administration, Dong-A University, BC-0116 3, 225 Gudeok-ro, Seo-gu, \\ Busan 49236, Korea; jhyang@dau.ac.kr \\ 2 Department of Tourism Management, Koje College, Majeon 1raod91, Geoje-si 53325, Korea \\ * Correspondence: ynnij@hanmail.net
}

check for updates

Citation: Yang, J.; Kim, B. Guilt and the Consumption of Products with an Unhealthy Image. Sustainability 2021, 13, 11953. https://doi.org/10.3390/ su132111953

Academic Editors: Valentina

Maria Merlino and Michael S. Carolan

Received: 17 September 2021

Accepted: 25 October 2021

Published: 29 October 2021

Publisher's Note: MDPI stays neutral with regard to jurisdictional claims in published maps and institutional affiliations.

Copyright: (c) 2021 by the authors. Licensee MDPI, Basel, Switzerland. This article is an open access article distributed under the terms and conditions of the Creative Commons Attribution (CC BY) license (https:// creativecommons.org/licenses/by/ $4.0 /)$.

\begin{abstract}
The purpose of this study was to investigate the effects of nutrition labeling on consumers' guilt when they consumed products with an unhealthy image. The first investigation was conducted to examine direct effect according to the types of nutrition labeling (adding healthy ingredients/reducing unhealthy ingredients) by independent samples $t$-test. The findings show that consumers felt less guilty when the number of unhealthy ingredients was reduced, compared to when healthy ingredients were added. The second investigation tested the effects of goal activation types (utilitarian/hedonic) and nutrition labeling on consumers' guilt by independent samples $t$-test and ANOVA. Goal activation was added as an independent variable, and hypothetical scenarios and stimulants were used. The experiment was designed with a focus on goal activation (utilitarian/hedonic) $\times$ nutrition labeling (adding healthy ingredient/reducing unhealthy ingredient). The findings reveal that the utilitarian goal activation group felt less guilty about the products with the reduction in the number of unhealthy ingredients than the products with the addition of healthy ingredients. The hedonic goal activation group felt less guilty about the products with the addition of positive nutrients compared to the products with the reduction in the number of negative nutrients. The third investigation tested consumer guilt in situations that create anxiety about food by independent samples $t$-test and ANOVA, based on Study 2. Unlike in Study 2, there was no interaction effect between product-nutrition labelling and goal activation. These results suggest that, when consumer anxiety increases, in relation to unhealthy foods that already invoke guilt and anxiety, the motivation-namely, goal activation when consuming food-plays a main role in causing anxiety, regardless of nutrition. Based on these experimental results, the investigator discussed the academic and practical implications of the present study. Finally, a couple of proposals were made for the direction of future study.
\end{abstract}

Keywords: product with an healthy/unhealthy image; guilt; nutrition labeling; goal activation; food-cue effects

\section{Introduction}

Guilt has played a critical role in mediating or moderating consumer choice [1-5] and consumer purchase intention [6-8]. In recent years, such studies have gradually changed to focus more on the psychological basis of guilt. Guilt can be categorized as a negative emotion; the guilt induced by consumption situations can limit consumer decision making $[6,7,9]$. Early studies have suggested ways of reducing guilt through personal effort, through self-control, maintaining emotional balance during specific actions, charity work, and various cues provided at the moment of purchase. Among various ways of reducing consumer guilt, studies of company-provided food cues mainly relate to food packaging [10-13]. These cues include highlighting the nutrition labels displayed on products [5,14-16], adjusting the price and composition of products [17], and providing additional cues [18], such as nutrition information [19].

The literature has gradually expanded to include research that predicts consumer behavior in response to provided food cues $[15,20]$, the positive or negative effects of 
nutritional product information [21], and consumer reactions to various types of nutrition labeling $[15,16,20,22]$. However, very few studies have explored either the shift in consumer guilt in various consumption situations or the limitations caused by inconsistent findings on the direction of nutritional information. This research aims to fill this gap by investigating changes in consumer guilt caused by product nutrition labelling and consumption-related goal activation, focusing on foods with an unhealthy image, such as instant and fast foods.

This paper presents three studies based on the theoretical background and logic needed to establish hypotheses and presents a research methodology and results that verify those hypotheses (Figure 1).

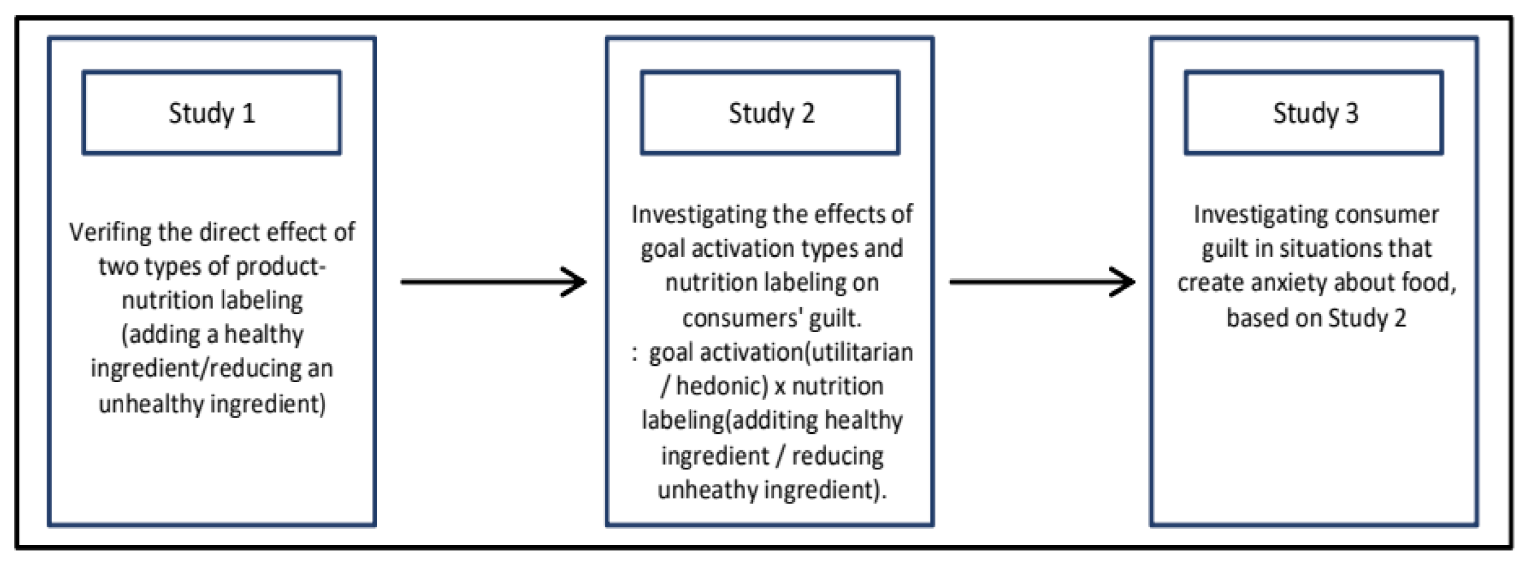

Figure 1. The framework of the entire investigation.

More specifically, this study aims to verify the effect of consumer guilt by labeling product ingredients in situations where unhealthy image products are ingested (Study 1). Next, given that consumer characteristics change, depending on the situation, Study 2 investigates the goal activation associated with ingesting unhealthy image products and the guilt caused by product nutrition labeling, based on Study 1 (Study 2). Lastly, consumer guilt is studied in situations that create anxiety about food, based on Study 2 (Study 3). Finally, the study concludes by reviewing various theoretical and practical implications based on the research results.

\section{Literature Review: Materials and Methods}

\subsection{Food-Cue Effects}

The product-attribute cues influencing consumer product evaluations can be divided into two main categories: extrinsic and intrinsic cues. Intrinsic cues present the physical characteristics or functions of the product itself, while extrinsic cues include product origins, advertisements, price, brand names, and other information attached to the product [23]. Most consumers tend to evaluate products based more on extrinsic than intrinsic cues [24]. As consumers have become more interested in health, ancillary food labeling related to food origins and unhealthy ingredients, and labelling related to nutrition and organic processing, have become important factors influencing consumer purchasing decisions $[25,26]$.

Previous studies of food cues have investigated consumer perceptions of the size and shape of food packaging [4,10,12,27]. Coelho do Vale et al. [11] and Scott et al. [12] examined the association between food consumption and packaging size (food in small vs. large containers). The findings showed that food consumption increased when the same product quantity was presented in several smaller containers, rather than one large container. This result was explained as consumers became sensitive to their own consumption when considering a large amount of food in one container; small containers decreased sensitivity, increasing consumption.

Research has also been conducted on consumer evaluations of product nutrition labels, moving beyond the shape and image of food packaging [14-16,26]. For example, consumers 
assessed products with "organic" labeling as low in calories and high in nutrition [15]; similarly, "low-fat" labeling made consumers perceive fewer calories, somewhat increasing food intake [14]. Donato et al. [26] have examined consumer perceptions by highlighting the positive and negative attributes of hotdogs, an unhealthy food. When their positive attributes were highlighted, health concepts became more accessible to consumers. As these results show, food-related cues play a decisive role in consumers' product judgments and emotions.

\subsection{Guilt}

Guilt is the emotion we feel when a moral, social, or ethical principle is violated [28]; it entails a process of psychological regret, along with a "guilty conscience" associated with the knowledge of having done something wrong [29,30]. Guilt arising from consumption situations has become a critical factor influencing consumer decision-making [31-34]. This pattern can lead to a reversal of existing preferences in selection situations [3,35]. Among the many previous studies, early research from Okada [3], which investigated consumers choice of grocery gift cards and dinner gift certificates. When two alternatives were separately presented, consumers attributed higher value to dinner gift certificates than to grocery gift cards. Consumer guilt was found to cause a reversal of preference when both alternatives were presented at the same time. In other words, the purpose of consumption caused guilt-inducing emotion in consumers seeking hedonic value in consumption situations, even though they were choosing between the same products [31,33].

Consumers also felt guilty when consuming products with hedonic attributes $[36,37]$. The psychological basis for this guilt was the perception that it was more difficult to "justify" the consumption of products with hedonic attributes or a hedonic purpose than the consumption of products with a utilitarian attribute or purpose [36]. While early studies of guilt focused on guilt-inducing factors, such as the purpose of products and consumption, most recent studies have focused on ways to reduce guilt during the decision-making and consumption processes $[4,6,38]$. Khan and Dhar [6] showed that a group engaging in moral behavior intended to purchase more luxury goods than a group that was not. This suggests a "licensing effect," which permits the purchase of hedonic products or the intake of high-calorie foods after good actions, such as charity activities. The positive self-esteem caused by altruistic behavior allows for hedonic consumption.

Mullen and Monin [4] have argued that people who have engaged in deviant behaviors in the past tend to undertake more reward-related behaviors (doing good things) in the present. Similarly, those who have done good things try to maintain their psychological balance by engaging in deviant behaviors. According to Oh et al. [9], when a subject has engaged in moral behavior, such as making a donation, his or her intention to purchase unhealthy food is higher than that of an individual who has engaged in immoral behavior. Related studies have researched ways of resolving guilt through both personal initiative and active corporate involvement.

\section{Developing Hypotheses}

\subsection{Guilt in Response to Product-Nutrition Labeling}

Prior research on eating and guilt has generally shown that guilt controls or mediates consumption; it has not attempted to mitigate guilt directly. To date, there are insufficient studies on the direct association between product nutrition labeling and guilt. However, the impact of guilt on directions in product nutrition labeling can be inferred from existing advertising messages and product cues. The present study deduces the presence of guilt when products or industries cause negative emotions. This occurs when products are considered unhealthy and viewed negatively.

First, a review of the literature on the positive and negative message-framing effect of advertising messages has uncovered studies of advertisements designed to make people stop smoking. These studies found that positive framing was effective for anti-smoking advertising, targeting tobacco companies, while negative framing had a positive effect 
on the intention to stop smoking [39]. Sundar et al. [40] classified nutritional information on fast-food menus as preferred and non-preferred foods; this investigation of purchase intentions and attitudes showed that purchase intention was stronger when preferred nutritional information was presented than when non-preferred nutritional information was presented. Although it is somewhat difficult to elicit consistent results, according to message direction through such studies, it is meaningful to investigate consumer perceptions of message framing by targeting products with negative images among consumers. In addition, the degree of guilt can be inferred, based on previous research on product cues. In a study of food packaging carried out by Silayoi and Speece [9], the visual aspect of packaging was related to the emotional aspect of the consumer's decision-making process, while informational elements, such as product nutrition, were related to consumer perceptions. Consumers also apply heuristics when selecting products. Instead of considering all healthy ingredients objectively, they base their decisions on ingredients they are interested in, such as fat [41]. Mishra and Mishra [17] found that consumers prefer discounted prices on unhealthy foods, such as chocolate, and bonus packs of foods with a healthy image, such as salads. The reason for this is that consumers can alleviate their guilt by coming up with a justifiable reason for making a particular choice.

When it comes to unhealthy food, Jiang and Lei [18] looked at cheesecake: when a healthy fruit topping was added, the cheesecake was perceived to be healthier than the equivalent cheesecake with no fruit topping. Overall, this study showed that toppings, although they constitute only a small part of food products, are used disproportionately to evaluate the general characteristics of food. Healthy toppings justify consuming food with an unhealthy image and thus reduce consumer guilt. Similarly, consumers tend to rate products positively, simply on the basis of their health-related claims [42]. Thus, claims that a food contains beneficial ingredients, such as vitamins or calcium, can act as a cue to induce a positive response from consumers [16,40]. We, therefore, infer that consumer guilt can be reduced through nutrition labeling and health-related claims.

Among various studies related to nutritional claims, Garreston and Burton [43] investigated consumer product evaluations in relation to the healthy ingredients listed in nutritional claims and on labels on the back of frozen food packaging. Their findings showed that, while differences in fat content (viewed as negative) affected nutritional attitude, brand attitude, and perception of disease risk, fiber content (viewed as positive) had no effect on product evaluation. Moreover, Kim and Yang [16] investigated the effect of the nutritional claims of two different healthy-image products on consumer product evaluations and perceptions of disease risk. Their research showed that, even when positive messaging about healthy ingredients was reinforced in products with a healthy image, the products were not considered healthier than ordinary products. By contrast, when ingredients seen as unhealthy were reduced, the products were considered healthier than ordinary products. In the case of products with an unhealthy image, adding healthy ingredients and reducing unhealthy ingredients both caused consumers to perceive the products as healthier. Thus, in the present study, based on Garreston and Burton [43] and Kim and Yang [16], consumer guilt about foods with an unhealthy image is likely to be mitigated more by reducing unhealthy ingredients than by adding healthy ingredients. Hypothesis 1 is therefore established, as follows:

Hypothesis 1. In a situation in which consumers ingest products with an unhealthy image, consumer guilt is lower for products with reduced unhealthy ingredients than for products with added healthy ingredients.

\subsection{Guilt Associated with Nutrition Labeling Products and Goal Activation}

Consumers experience maximum conflict when their goals and behaviors diverge in relation to food choice [44]. When such conflicts arise, consumers must have reasonable evidence to justify their consumption [45]. Consumers provide a basis for justifying their consumption through various purposes in the purchasing situation [46]. In particular, 
product choice can be modified by different purposes (e.g., utilitarian or hedonic), which can affect information processing and consumer justification [47]. Most previous research on types of consumption purpose have shown that hedonic consumption causes more guilt than utilitarian consumption. In other words, consumers tend to choose an alternative that is easy to clarify, because it is easier to justify a choice in a utilitarian consumption situation than in a hedonic consumption situation [46]. This suggests that the productchoice process, carried out with utilitarian, hedonic, or other goals in mind, can affect the processing of consumer information [47]. In short, when consumers are exposed to different environmental cues, their consumption is activated by different goals. A specific stimulus activates each goal and makes choices to achieve that goal [48].

In a study related to consumer choice by goal activation, Dhar and Wertenbroch (2000) [35] found that consumers tended to prefer utilitarian products when they were focused on acquisition tasks, and hedonic products when they were focused on forfeiturerelated tasks. According to Park [49], who expanded the findings of Dhar and Wertenbroch [35], the relative increase in preferring hedonic products during the forfeiture task shows that consumer guilt plays a moderating role.

We can thus infer that a product with reduced unhealthy ingredients in a utilitarian goal activation situation and a product with added healthy ingredients in a hedonistic goal activation situation will both induce less guilt. This result can be described as the "cleansing effect". If previous behavior was immoral, subsequent behavior tends to involve decisions designed to wash away the previous immoral behavior [9,50]. Consuming foods with an unhealthy image can be understood within the same context. In light of prospect theory from Tversky and Kahneman [51], consumers also have loss aversion, reacting more sensitively to losses than to gains. They are likely to react more to negative product-related information than to positive information. We, therefore, propose the following hypothesis, anticipating that the consumer response to goal activation will be more pronounced in the case of unhealthy ingredients than healthy ones.

Hypothesis 2. In a situation in which unhealthy-image products are being consumed, the effect of consumer-goal activation on guilt will differ in accordance with the nutrition labeling.

Hypothesis 2a. In a utilitarian goal activation situation, less consumer guilt will be induced by products with reduced unhealthy ingredients than by products with added healthy ingredients.

Hypothesis 2b. In a hedonic goal activation situation, products with added healthy ingredients will induce less consumer guilt than products with reduced unhealthy ingredients.

Hypothesis 3. In a situation in which unhealthy image products are being consumed, consumer goal activation will have more impact on guilt if the products have reduced unhealthy ingredients than if they have added healthy ingredients.

\subsection{Guilt in Anxiety-Provoking Situations}

Taylor [52] introduced the concept of consumer anxiety and studied the process of inducing anxiety through uncertainty related to possible outcomes in the context of choice, which led to risk perception. Sah and Yeo [22] defined consumer anxiety as an emotion, such as tension or anxiety, felt during the whole consumption process; this represents an expansion of consumer anxiety in purchasing situations proposed by Taylor [52]. Even when consumers experience the same risk, there may be individual differences in the anxiety they feel, especially when confronting uncontrollable or unknown risks [53]. In recent years, as access to information has improved, food-related anxiety and risk perception (previously not well understood) have been increasing; negative food-related emotions are likely to cause risk perception [54].

Earlier studies have attempted to clarify the hazard attributes that influence risk perception. Among these, specific hazards associated with food have been activated in the process of consumer perception, influencing food judgment [55-57]. Jun [57] has also 
studied consumer purchasing behavior around eco-friendly products and the consumptionsatisfaction process. The higher the consumer anxiety about food, the higher the intention to purchase eco-friendly products. Sah and Yeo [22] have investigated factors affecting anxiety, along with levels of consumer anxiety related to GM foods, unhealthy ingredients, and mad cow disease. The factors that cause anxiety are the consumer's objective and subjective knowledge, belief in the medium providing information, and risk perception. According to this study, consumers showed the highest level of anxiety about mad cow disease. The differences in anxiety perception were presented differently, depending on demographic characteristics, such as age and social and cultural background, including political orientation.

Hypothesis 4. In a situation where unhealthy image products are being consumed, there will be no difference between a product with a healthy ingredient added and a product with an unhealthy ingredient reduced in terms of the effect of consumer goal activation on guilt, when product anxiety is increased.

\section{Methodology}

This research consisted of two experimental studies of consumer guilt associated with product nutrition labeling and goal activation. Study 1 investigated the direct effect of product nutrition labeling by independent samples $t$-test, while Study 2 examined consumer guilt caused by product nutrition labeling and goal activation by independent samples $t$-test and ANOVA. Study 3 expanded Study 2, investigating consumer guilt when consumer anxiety about unhealthy food increased by independent samples $t$-test and ANOVA.

\subsection{Study 1}

Study 1 set out to verify the direct effect of two types of product-nutrition labeling (adding a healthy ingredient/reducing an unhealthy ingredient) in order to investigate the effect of product-nutrition labeling on consumer guilt in situations where products perceived as unhealthy were being consumed. A survey was conducted with undergraduate and graduate college students in Dong-a University, Busan, in Korea as the subjects to test the hypotheses. Product nutrition labeling was separating into two groups: labeling with an added healthy ingredient and labeling with an unhealthy ingredient reduced. Appropriate stimuli were then presented. The mean difference between product nutrition labeling and consumption according to guilt was investigated to determine the effect of each group. Based on the pre-test, a virtual brand was used; there were 30 participants in each group experiment.

\subsubsection{Pre-Test}

We conducted a pre-test to select a product to test. It was important for the product to be familiar to many people; considered unhealthy by many people; able to have healthy ingredients added or reduced. An FGI (Focus Group Interview) was carried out with five graduate students to select ten products (pizza, chocolate, ice cream, ramen, chicken, frozen dumplings, mixed coffee, cola, hamburger, and fried food). To choose the product with the most unhealthy-looking image, a survey of 30 undergraduate students was carried out. To gather opinions of each product, Wertenbroch's [1] study was revised to fit this study. For each food, the students rated 3 items, using a 5-point scale (1 likely to have low levels of a healthy ingredient- 5 likely to have high levels of a healthy ingredient; 1 likely to be unhealthy-5 likely to be healthy; 1 I do not feel that this food is healthy-5 I feel that this food is healthy). The means were derived in the following order for pizza, ramen, coke, hamburger, chocolate, ice cream, mixed coffee, fried food, frozen dumplings, and chicken. The difference between pizza and ramen, which had the highest mean values, was found to be insignificant, so a pre-test survey was conducted on these two products alone. These products were presented to 20 undergraduate students, who completed a 
simple questionnaire to choose the product with the unhealthier image; 7 students chose pizza and 13 chose ramen. Ramen was, therefore, selected as the product with the most unhealthy-looking image; instant cup noodles had the least-healthy image among various ramen products. As the next section involved food nutrition labeling, ingredients were collected from the website of the ramen company; they included protein, carbohydrate, fat, trans fat, saturated fat, cholesterol, calcium, sodium, sugar, and dietary fiber. Just as in the product-selection process, five graduate students were allowed to freely discuss the ingredients that should be added or reduced to improve the healthiness of instant ramen, regardless of taste or flavor, as in the FGI method. After some discussion, dietary fiber was selected as the best healthy ingredient to add to ramen, and sodium was selected as the ingredient to reduce, given the nature of ramen and the need to properly harmonize any changes.

\subsubsection{Main Study}

For Study 1, two cup-noodle advertising stimulants were created. A black-and-white image of the cup-noodle container was shown to the experiment participants. It was important not to use an actual ramen brand, which would have triggered participants' usual responses, regardless of the product nutrition labeling or goal activation. We therefore created a virtual brand, "The Ramen". The brand name, as a stimulus, was placed at the top and the ingredients were placed at the bottom. The healthy ingredient was added as follows: "with 50\% more dietary fiber than the recommended daily amount of dietary fiber". The unhealthy ingredient was flagged as " $50 \%$ less sodium than ordinary ramen". Then, on the assumption that the product was consumed, the association between consumer guilt and product-nutrition labeling was investigated. Sixty undergraduate and graduate students were separated into two groups, using a convenient sampling method. The participants were randomly assigned to two experimental situations, each consisting of 30 people. In this study, consumer guilt related to product consumption was selected as the dependent variable. Since guilt is a negative emotion, involving consumption-related regret and shame, the scale used by Kivetz and Simonson [31] was modified and used for this study, with a focus on food consumption. Specifically, the questions involved the feelings of a certain " $\mathrm{A}$ " after eating cup noodles: "I think A was being careless about his/ her health when he/she ate cup noodles;" "Eating cup noodles isn't good for A's body;" "If A thinks about his/her health, I think he/she will regret eating cup noodles;" and "A seems to feel guilty about eating ramen." The participants' responses were measured using a 7-point Likert scale $(\alpha=0.784)$.

\subsubsection{Results}

Study 1 set out to examine the effect of product-nutrition labeling on consumer guilt. To achieve this, an independent sample $t$-test between the 2 stimuli was conducted; it showed a significant difference in the mean of guilt, according to product-nutrition labeling $(\mathrm{t}(58)=-4.241, p<0.001)$. Guilt was reduced in the unhealthy-ingredient-reduction group $(\mathrm{M}=4.45(\mathrm{sd}=1.19))$ more than in the healthy-ingredient-addition group $(\mathrm{M}=5.31$ $(\mathrm{sd}=1.03))$. Thus, Hypothesis 1 was supported; in a situation in which an unhealthyimage product is ingested, consumer guilt is lower for products with reduced unhealthy ingredients than for products with added healthy ingredients.

\subsection{Study 2}

Study 2 was conducted to test Hypotheses 2 and 3, which argued that consumer guilt due to consuming unhealthy-image products would differ, depending on the type of product nutrition labeling and goal activation. First, goal activation was divided into utilitarian and hedonic goal activation, making it possible to examine the nutrition labeling effect of each type of activation. Second, we investigated which type of product labeling had a greater effect on goal activation. 


\subsubsection{Main Study}

The scenario assumed the following four experimental conditions: 2 (goal activation: utilitarian vs. hedonic) $\times 2$ (product nutrition labeling: adding a healthy ingredient vs. reducing an unhealthy ingredient) of consumption goal activation and product nutrition labeling. In addition, for the comparison of measurement results, a control group without guilt was added and investigated. The experiments were conducted using a betweensubject design. Before the main study, in order to divide goal activation into utilitarian and hedonic types, the participants' behaviors (utilitarian: relieving hunger vs. hedonic: for pleasure) when it comes to eating food were investigated from the prior survey based on the study of Shao \& Li [7]. Additionally, then they were classified into two types to assign each experimental condition. A total of 128 students who majored in business administsration in Dong-a Unversity, Busan in Korea participated in the experiment and 120 completed questionnaires were used for the study, excluding 8 respondents whose responses were insincere. Undergraduate and graduate students were chosen for this experiment using a convenience sampling method; the participants were randomly assigned to all four experimental conditions. Each experimental group consisted of 30 people, who were under the control of the experimenter for about $10 \mathrm{~min}$ to ensure accurate results. In the goal activation situation, the utilitarian goal activation involved a situation in which an individual had to eat to relieve hunger; the hedonic goal activation involved a situation in which an individual ate food for taste and enjoyment of consumption. Specially, cup noodles selected as a stimulus is recognized as a utilitarian product emphasizing convenience for cooking and eating. According to the study of Park [58], however, when consumers have a wide range of food choices, they recognize ramen as a hedonic product because consumers seeking simple foods makes them include hedonic options which are inferior in the hierarchy of needs. This could be the basis for the ramen selected as a stimulus in this study. The stimulus, a cup-noodle container, was presented as a black-and-white image file. As in Study 1, the virtual ramen brand was called "The Ramen." The arrangement and composition were produced in the same way as the stimulus in Study 1. For the goal activation element, the scenario was produced in two ways, as a first-person view and a third-person view. Participants were asked for their opinions about the scenario. Applying the scale used in Feick and Higie [58], participants responded using a 5-point scale to questions related to the following points: "I think the situation presented in the scenario could actually occur" and "the reality of the content described in the scenario." The mean of the first-person view was 3.04 and the mean of the third-person view was 4.10; the difference between the two groups was significant. Using these results, a scenario from the third-person point of view was constructed. A comment about "assuming that ' $A$ ' in the scenario is me" and asking for a questionnaire was included at the beginning of the scenario.

\subsubsection{Manipulation Check}

In the study experiments, questions were asked to ensure that participants were able to distinguish between utilitarian and hedonic goals in the goal activation section. When asked about a utilitarian goal, 8 subjects responded with a hedonic goal; when asked about a hedonic goal, 2 subjects incorrectly responded with a utilitarian goal. In addition, in the nutrition-labeling section, 8 subjects responded incorrectly to a question about healthy-ingredient labeling. In this study, responses that were inconsistent with those of the experimental group during the manipulation check were treated as insincere and were excluded from the analysis. Finally, in relation to questions about reality, the possibility of the occurrence, and whether the scenario could be imagined, the mean of the 3 questions was 5.93. Although there were no clear interpretation criteria, all three items showed a median value of 4 or more; thus, the participants judged the experimental situation to be acceptable in real life. 


\subsubsection{Results}

- A. Characteristics of the Sample

The characteristics of the 120 survey respondents used in the analysis were as follows: most of the respondents were in their 20s, with those aged 22-26 accounting for $90 \%$ of the total. The gender ratio was evenly distributed, with $46.7 \%$ males and $53.3 \%$ females. As for their ramen-eating habits, $18.3 \%$ of the respondents consumed ramen 3 or more times per week. The largest group (34.2\%) ate ramen $1-2$ times per week; $27.5 \%$ ate ramen $2-3$ times a month; $6.7 \%$ ate ramen once a month, and $13.3 \%$ rarely ate ramen.

- B. Verification of Hypothesis 2

In order to test Hypothesis 2, participants in the goal activation section were divided into a utilitarian goal activation group and a hedonic goal activation group; an independent sample $t$-test related to product-nutrition labeling was carried out in each group. In the utilitarian goal activation group, the difference in guilt related to product nutrition labeling was statistically significant $(\mathrm{t}(58)=2.849, p<0.008)$. In the hedonic goal activation group, guilt related to product nutrition labeling was lower in products with a reduced unhealthy ingredient $(\mathrm{M}=4.03(\mathrm{sd}=0.97)$ than in products with an increased healthy ingredient $(\mathrm{M}=4.86$ $(\mathrm{sd}=1.27)$. These results show that Hypothesis 2a, "In a utilitarian-goal-activation situation, less consumer guilt will be induced by products with reduced unhealthy ingredients than by products with added healthy ingredients," was supported. Next, in the hedonic group, the mean difference was verified, according to product nutrition labeling, and the difference in guilt related to product nutrition labeling was statistically significant $(\mathrm{t}(58)=-2.475$, $p<0.016)$. In the hedonic group, consumer guilt caused by product nutrition labeling was lower for products with an increased healthy ingredient $(\mathrm{M}=5.63$ (sd 0.88)) than in products with a reduced unhealthy ingredient ( $\mathrm{M}=5.00$ (sd 1.08)). Consequently, Hypothesis $2 \mathrm{~b}$ was also supported. Lastly, comparing the control group without guilt and the experimental group, there was a statistically significant difference among them $(F=9.62, p$ $<0.01$ ). These results show that it is useful to reduce ingredients perceived as unhealthy in products considered unhealthy when consumers are activated to achieve a utilitarian goal. In contrast, adding healthy ingredients is a better strategy when the hedonic goal is activated.

- C. Verification of Hypothesis 3

Hypothesis 3 was tested using an analysis of variance (ANOVA) to examine the twoway interaction effect between goal activation and product nutrition labeling during the consumption of unhealthy image products. The mean and standard deviations for each experimental group are shown in Table 1.

Regarding the variance analysis shown in Table 2, product nutrition labeling and goal activation were found to have a significant interaction ( $\mathrm{F}=14.24, p<0.000)$. Thus, Hypothesis 2 was supported. Specifically, as shown in Figure 2, which shows the moderating effect, there was little difference in the case of products with added healthy ingredients, regardless of goal activation. For products with reduced unhealthy ingredients, the degree of guilt varied in accordance with the goal activation. These results reveal that products with added healthy ingredients show little difference, regardless of goal activation. By contrast, in products with reduced unhealthy ingredients, the degree of guilt varies, depending on the goal activation. 
Table 1. The mean and SD of unhealthy image food consumption by goal activation and nutrition labeling.

\begin{tabular}{|c|c|c|c|c|c|c|c|}
\hline & & \multicolumn{4}{|c|}{ Goal Activation } & \multirow{2}{*}{\multicolumn{2}{|c|}{ Total }} \\
\hline & & \multicolumn{2}{|c|}{$\begin{array}{c}\text { Utilitarian } \\
\text { Goal Activation }\end{array}$} & \multicolumn{2}{|c|}{$\begin{array}{c}\text { Hedonic } \\
\text { Goal Activation }\end{array}$} & & \\
\hline & & Mean & SD & Mean & SD & Mean & SD \\
\hline \multirow{3}{*}{$\begin{array}{l}\text { Nutrition } \\
\text { Labeling }\end{array}$} & $\begin{array}{c}\text { Adding } \\
\text { healthy ingredient } \\
\text { (dietary fiber) }\end{array}$ & 4.86 & 0.97 & 5.00 & 1.08 & 4.93 & 1.02 \\
\hline & $\begin{array}{l}\text { Reducing unhealthy } \\
\text { ingredient (sodium) }\end{array}$ & 4.03 & 1.27 & 5.63 & 0.89 & 4.83 & 1.30 \\
\hline & Total & 4.45 & 1.19 & 5.31 & 1.03 & & \\
\hline
\end{tabular}

The mean of guilt in Table 1 indicates that products with reduced unhealthy ingredients ranked higher in the hedonic activation situation, while products with reduced unhealthy ingredients ranked lower in the context of utilitarian goal activation.

Table 2. The results of the variance analysis of consuming unhealthy image food by goal activation and nutrition labeling.

\begin{tabular}{ccccc}
\hline Variance & SS & df & MS & F \\
\hline A. Goal activation & 22.53 & 1 & 22.53 & $19.89 * * *$ \\
B. Nutrition Labeling & 0.30 & 1 & 0.30 & 0.26 \\
A $\times$ B & 16.13 & 1 & 16.13 & $14.24^{* * *}$ \\
error & 131.40 & 116 & 1.13 & \\
Total & 3032.00 & 120 & &
\end{tabular}

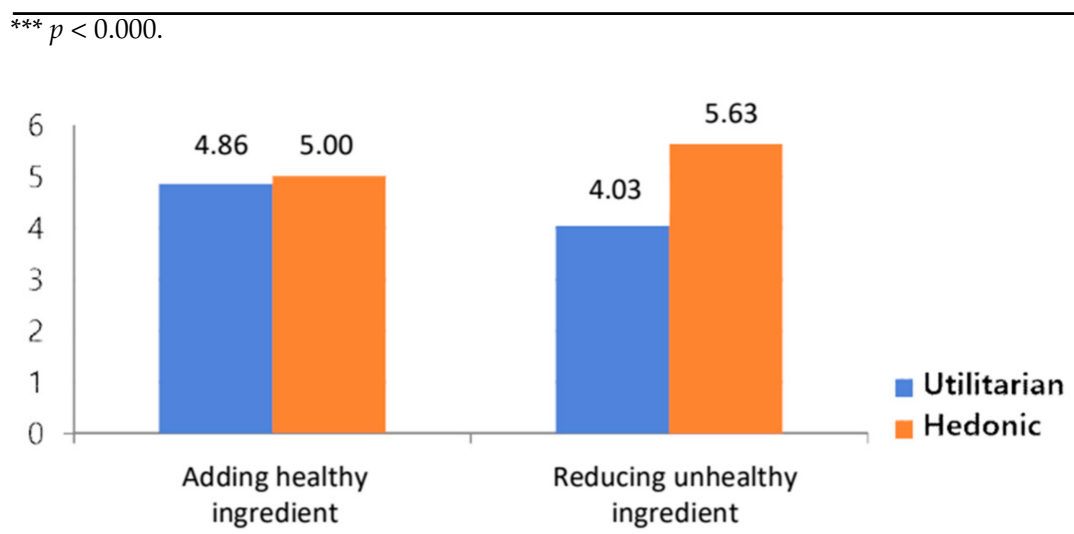

Figure 2. The mean difference of unhealthy-image food consumption by goal activation and nutrition labeling.

\subsection{Study 3}

Study 3 was carried out to verify Hypothesis 4 , "In a situation where unhealthy-image products are being consumed, there is no difference between a product with a healthy ingredient added and a product with an unhealthy ingredient reduced in terms of the effect of consumer goal activation on guilt, when product anxiety is increased". Goal activation was divided into two categories (utilitarian and hedonic), as in Study 2, to discover which type of product labeling had a greater influence on guilt.

\subsubsection{Main Study}

The scenario presented anxiety about the experimental product, and then consumption goal activation 2 (goal activation: utilitarian vs. hedonic) nutrition labeling 2 (product nutrition information: adding healthy ingredient vs. reducing unhealthy ingredient). Four experimental conditions were created, constituting the between-subject design. In addition, for the comparison of measurement results, a control group without anxiety was added 
and investigated. A total of 120 students participated in the experiment. Undergraduate and graduate students who are majoring in business administration in Dong-a University, Busan in Korea were chosen for the experiment using a convenience sampling method; the participants were randomly assigned to all four experimental conditions. Each experimental group consisted of 29-31 participants, who were under the control of the experimenter for about $10 \mathrm{~min}$ to ensure accurate results. As an experimental stimulus designed to show anxiety about the product, the newspaper-article method was adopted. Consumer access to information can be divided into temporary and long-term accessibility because news media and news reports are frequently activated on a temporary basis, making it easy to temporarily increase accessibility. Furthermore, news reports are a medium believed to have high consumer confidence, among various sources of information. For this reason, an online newspaper article was produced as a stimulus; the article stated that ramen, the experimental stimulus, increased the risk of various diseases. The rest of the stimuli were created in the same manner as in Study 2.

\subsubsection{Manipulation Check}

To carry out the manipulation check for anxiety, the first questions were about the article. Out of 5 items, 3 were related to the newspaper article, and 2 were not. In total, 62 participants $(75 \%)$ selected 3 questions related to the newspaper article, while $16(20 \%)$ selected 2 questions. Thus, about $95 \%$ of the participants were found to be aware of content of the experimental article. Moreover, in questions about reality, the possibility of the occurrence, and whether the scenario could be imagined, the mean of the 3 questions was 5.63. Although there were no clear interpretation criteria, all three items showed a median value of 4 or more, and the participants judged the experimental situation to be acceptable in real life.

\subsubsection{Results}

\section{- A. Characteristics of the Sample}

The characteristics of the 83 survey respondents were as follows: most of the respondents were in their 20s, with those aged 22-26 accounting for $98 \%$ of the total. The gender ratio was evenly distributed, with $40(48 \%)$ males and $43(52 \%)$ females. As for their ramen-eating habits, $13(16 \%)$ respondents consumed ramen 3 or more times a week. The largest group (40 (48\%)) ate ramen 1-2 times per week; 18 (22\%) ate ramen 2-3 times a month; $5(6 \%)$ ate ramen once a month, and $7(8 \%)$ rarely ate ramen.

\section{- $\quad$ B. Verification of Hypothesis 4}

Assuming a state of increased consumer anxiety about the product, Hypothesis 4 was tested using an ANOVA to examine the two-way interaction effect between goal activation and product nutrition labeling when consuming an unhealthy-image product. The mean and standard deviation for each experimental group are shown in Table 3. Specifically, the mean of guilt in Table 3 shows that products with added healthy ingredients ranked higher in the hedonic goal activation situation, while products with reduced unhealthy ingredients ranked lower in the context of utilitarian goal activation. These results differ from those in Study 2, which did not present an anxiety situation. In Study 2, the product with reduced unhealthy ingredients was associated with a higher level of consumer guilt in the hedonic goal activation situation.

As a result of the variance analysis shown in Table 4, product nutrition labeling and goal activation were found to have an insignificant interaction $(\mathrm{F}=0.76 p<0.38)$. Thus, Hypothesis 4 was rejected. Specifically, as shown in Figure 3, guilt was generally higher in the hedonic goal activation situation than in the context of utilitarian goal activation. Lastly, comparing the control group without anxiety and the experimental group, there was a statistically significant difference among them $(\mathrm{F}=18.248 p<0.01)$. This result is different from that of Study 2: as consumer anxiety about the product increased, the mean of guilt overall also increased; the interaction effect of the two variables was not significant. 
Table 3. The mean and SD of consuming unhealthy-image food by goal activation and nutrition labeling under product anxiety.

\begin{tabular}{|c|c|c|c|c|c|c|c|}
\hline & & \multicolumn{4}{|c|}{ Goal Activation } & \multirow{2}{*}{\multicolumn{2}{|c|}{ Total }} \\
\hline & & \multicolumn{2}{|c|}{$\begin{array}{c}\text { Utilitarian } \\
\text { Goal Activation }\end{array}$} & \multicolumn{2}{|c|}{$\begin{array}{c}\text { Hedonic } \\
\text { Goal Activation }\end{array}$} & & \\
\hline & & Mean & SD & Mean & SD & Mean & SD \\
\hline \multirow{3}{*}{$\begin{array}{l}\text { Nutrition } \\
\text { Labeling }\end{array}$} & $\begin{array}{c}\text { Adding } \\
\text { healthy ingredient } \\
\text { (dietary fiber) }\end{array}$ & 4.98 & 1.05 & 5.79 & 0.87 & 5.39 & 0.99 \\
\hline & $\begin{array}{l}\text { Reducing unhealthy } \\
\text { ingredient (sodium) }\end{array}$ & 4.53 & 1.08 & 5.50 & 0.60 & 5.02 & 0.99 \\
\hline & Total & 4.75 & 1.07 & 5.65 & 0.74 & 5.21 & 0.99 \\
\hline
\end{tabular}

Table 4. The results of the variance analysis of consuming unhealthy-image food by goal activation and nutrition labeling.

\begin{tabular}{ccccc}
\hline Variate & SSS & df & MS & F \\
\hline A. Goal activation & 11.63 & 1 & 11.63 & $13.54^{* * *}$ \\
B. Nutrition Labeling & 1.57 & 1 & 1.57 & 1.83 \\
A $\times$ B & 0.65 & 1 & 0.65 & 0.76 \\
error & 67.87 & 79 & 0.86 & - \\
Total & 2258.00 & 120 & - & - \\
\hline
\end{tabular}

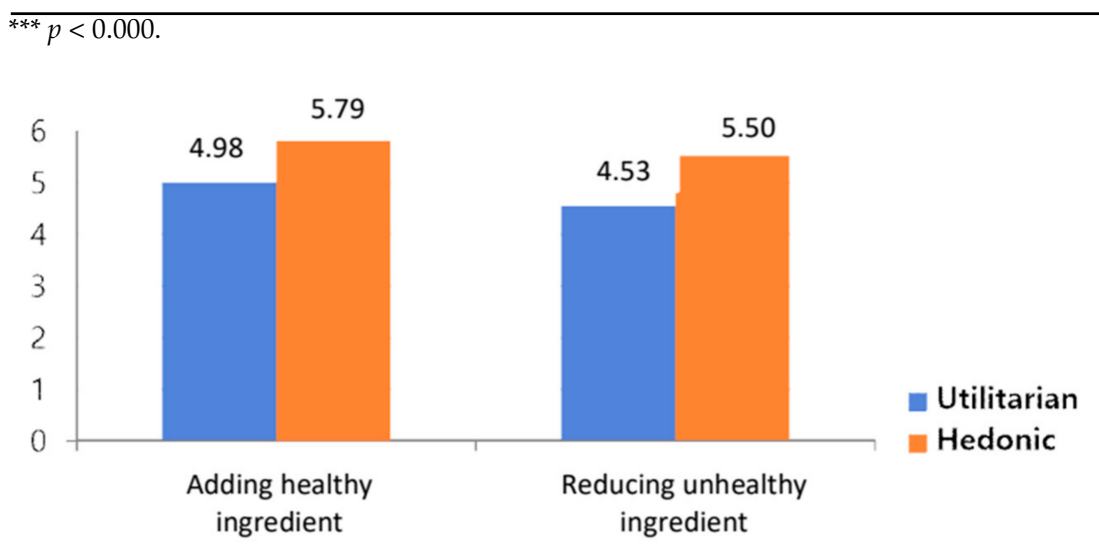

Figure 3. The mean difference of consuming unhealthy-image food by goal activation and nutrition labeling in product anxiety.

\section{Conclusions}

\subsection{Results}

In recent years, more consumers have become concerned about their health and increasingly interested in product ingredients and nutrition labels, unhealthy ingredients, and health foods. There has also been a steadily increasing consumer trend of searching for eco-friendly and organic products. However, there is also a contrasting phenomenon: more and more people are looking for convenience foods and turning to handy meals, due to busy schedules and a lack of time. The market for convenience-store lunchboxes and ready-tocook food is growing. These contradictory phenomena arise from the increasing number of situations in which unhealthy foods are consumed for various reasons, including cost and time, by people who aim to pursue a healthy lifestyle. It has therefore become important to find factors that reduce the guilt associated with eating unhealthy foods in modern society. The present study has empirically analyzed the way in which the negative emotion of guilt, in situations involving consumer consumption of unhealthy-image products, varies according to product nutrition labeling and consumer goal activation. The findings confirm 
a method of reducing the guilt that consumers feel when consuming unhealthy-image products. The research results are summarized below.

First, Study 1 verifies that consumer guilt differs, depending on product-nutrition labeling. Instant cup noodles were chosen as a stimulant, and the results of the two groups (one with an added healthy ingredient and the other with a reduced unhealthy ingredient) were compared. Guilt was found to be lower in the group exposed to a product with a reduced unhealthy ingredient than in the group with an added healthy ingredient. For products perceived negatively, these results were in line with those of Ketron et al. [59], in which negative framing had a greater effect on advertising than positive framing.

Second, Study 2 expands on Study 1, starting from the presumption that the degree of guilt is likely to differ when consumers activate utilitarian or hedonistic goals in situations where unhealthy-image foods are consumed. Using the scenario technique, consumer goal activation was manipulated, confirming a difference in consumer guilt between the utilitarian goal activation group and the hedonic goal activation group. Specifically, when the consumer's utilitarian goals were activated, the guilt caused by the consumption of unhealthy-image products was lower for products with reduced unhealthy ingredients than for those with added healthy ingredients. In contrast, in the context of hedonic goal activation, the guilt caused by the consumption of unhealthy-image products was lower for products containing an added healthy ingredient than for those with a reduced unhealthy ingredient. As in Khan and Dhar [6], this result shows that future behavior may vary, depending on the purpose of consumption.

Third, a statistically significant interaction effect was found in Study 2 when verifying the interaction effect of product-nutrition labeling and goal activation in relation to the impact of consumer goal-activation on guilt. Specifically, the impact of consumer goal activation on guilt was greater in products with reduced unhealthy ingredients than in products with added healthy ingredients. In other words, in unhealthy-image foods with added healthy ingredients, there was little difference caused by goal activation. However, for products with reduced unhealthy ingredients, guilt tended to increase when the hedonic consumption goal (as opposed to the utilitarian consumption goal) was activated. These results are in line with Tversky and Kahneman's [51] prospect theory, which states that consumers are more sensitive to losses than gains, due to a loss-aversion tendency. Similar results were derived here, showing higher sensitivity to loss than gain in unhealthy-image products.

Fourth, Study 3, which expanded on Study 2, investigated consumer guilt in situations with increased food anxiety. Unlike Study 2, Study 3 did not find an interaction effect between product nutrition labeling and goal activation. These results suggest that, when consumer anxiety increases in relation to unhealthy foods that already invoke guilt and anxiety, the motivation-namely, goal activation when consuming food-plays the main role in causing anxiety, regardless of nutrition.

\subsection{Implications}

The results of this empirical analysis have the following implications. First, when consumers ingest unhealthy-image products, their guilt is lower in utilitarian goal activation situations than in hedonic goal activation situations. Based on these results, it is important to emphasize the utilitarian aspect of these findings for marketers advertising unhealthy-image products or issuing marketing communications. Indeed, Nongshim promoted Shin Ramen Black Cup noodles by including the phrase: "Don't skip your morning meal" at the end of an advert. In other words, by simply telling consumers that they could eat ramen in the morning, the advert emphasized the utilitarian aspect of breakfast, rather than the flavor of ramen. Thus, companies that emphasize the utilitarian function of unhealthy-image products, rather than attributes, such as flavor and pleasure, will be able to promote consumption while reducing consumer guilt.

Second, products with a reduced unhealthy ingredient in the utilitarian goal activation situation, and products with an added healthy ingredient in the hedonic goal activation sit- 
uation were associated with lower levels of guilt. In the case of unhealthy-image products, a different nutrition labeling strategy can, therefore, be used, once the utilitarian orientation has been distinguished from the hedonic orientation. In marketing communications, if a utilitarian goal activation is chosen, the strategy of reducing unhealthy ingredients should be used; if hedonic goal activation is chosen, it would be better to emphasize added healthy ingredients.

Lastly, when it comes to unhealthy-image products, adding healthy ingredients changed very little in the context of utilitarian or hedonic goal activation. However, reducing unhealthy ingredients had a different impact, depending on the type of goal activation. It is clear that, when an unhealthy ingredient is eliminated from an unhealthyimage product, more careful selection and labeling are required. In particular, as consumers feel guilty for consuming unhealthy-image products, this study shows that their guilt can be amplified by mentioning unhealthy ingredients.

\subsection{Limitations and Directions for Future Research}

This study has some limitations. First, although ramen, which has an unhealthy image, has been used by many researchers as a stimulant, the results of this study cannot be generalized to every context. In addition, a third-person scenario was used to test the goal-activation situation; other effects are possible, depending on the consumer's actual situation. Although suitability was supplemented to some extent through a pretest, it is difficult to rule out the possibility that other factors could be involved. Second, when it comes to nutrition labeling, both positive and unhealthy ingredients were tested; however, guilt related to products without nutrition labeling (via a control group) was not investigated. The following directions for future research can overcome these limitations. First, additional research is needed to ascertain whether other unhealthy-image products would produce the same results. Second, there is also a need for research on guilt in the absence of nutrition labeling. Future studies should also consider other variables that can reduce the guilt felt when choosing an unhealthy-image product. Third, this research should be expanded by including other products and situations that can cause guilt.

Author Contributions: Conceptualization, J.Y. and B.K.; methodology, J.Y.; validation, J.Y. and B.K.; formal analysis, J.Y.; investigation, B.K.; resources, J.Y.; data curation, J.Y.; writing-original draft preparation, J.Y.; writing-review and editing, B.K.; visualization, B.K.; supervision, B.K.; project administration, J.Y.; funding acquisition, J.Y. All authors have read and agreed to the published version of the manuscript.

Funding: This study was supported by the Dong-A University intramural research grant.

Institutional Review Board Statement: Ethical review and approval were waived for this study, because the Institutional Review Board of Dong-A University does not require the full review process for the consumer acceptance research involving benign behavioral interventions and collecting data from an adult subject through verbal or written responses.

Informed Consent Statement: Informed consent was obtained from all participants in the study.

Acknowledgments: The authors would like to thank all reviewers to give good advice to improve this study.

Conflicts of Interest: The authors declare no conflict of interest.

\section{References}

1. Wertenbroch, K. Consumption Self-Control by Rationing Purchase Quantities of Virtue and Vice. Mark. Sci. 1998, 17, 317-337. [CrossRef]

2. Dhar, R.; Simonson, I. Making Complementary Choices in Consumption Episodes: Highlighting versus Balancing. J. Mark. Res. 1999, 36, 29-44. [CrossRef]

3. Okada, E.M. Justification Effects on Consumer Choice of Hedonic and Utilitarian Goods. J. Mark. Res. 2005, 42, 43-53. [CrossRef]

4. Mullen, E.; Monin, B. Consistency Versus Licensing Effects of Past Moral Behavior. Annu. Rev. Psychol. 2016, 67, 363-385. [CrossRef] [PubMed] 
5. Lunardo, R.; Saintives, C.; Chaney, D. Food packaging and the color red: How negative cognitive associations influence feelings of guilt. J. Bus. Res. 2021, 134, 589-600. [CrossRef]

6. Khan, U.; Dhar, R. Licensing Effect in Consumer Choice. J. Mark. Res. 2006, 43, 259-266. [CrossRef]

7. Min, D. The Influences of Charity and Negative Perception of Production on Purchase Intent toward Luxury brand: Focusing on the Mediating Effect of Guilt Reduction. J. Digit. Converg. 2016, 14, 85-91. [CrossRef]

8. Yu, H.; Chambers, E.; Koppel, K. Exploration of the food-related guilt concept. J. Sens. Stud. 2020, 36, e12622. [CrossRef]

9. Oh, M.J.; Kim, E.B.; Park, J.C. Irrational consumption patterns in the sequential consumption: Focusing on licensing effect and cleansing effect. Korean J. Consum. Advert. Psychol. 2014, 15, 665-685. [CrossRef]

10. Silayoi, P.; Speece, M. The importance of packaging attributes: A conjoint analysis approach. Eur. J. Mark. 2007, 41, 1495-1517. [CrossRef]

11. Coelho, D.V.; Pieters, R.R.; Zeelenberg, M. Flying under the Radar: Perverse Package Size Effects on Consumption Self-Regulation. J. Consum. Res. 2008, 35, 380-390. [CrossRef]

12. Scott, M.L.; Nowlis, S.M.; Mandel, N.; Morales, A.C. The Effects of Reduced Food Size and Package Size on the Consumption Behavior of Restrained and Unrestrained Eaters. J. Consum. Res. 2008, 35, 391-405. [CrossRef]

13. Kim, J.H.; Ha, H.R. The effect of small package size on self-control intention: Focus on the isolation effect and regulatory focus. Korean J. Consum. Advert. Psychol. 2015, 16, 309-332.

14. Wansink, B.; Chandon, P. Can “Low-Fat" Nutrition Labels Lead to Obesity? J. Mark. Res. 2006, 43, 605-617. [CrossRef]

15. Chandon, P.; Wansink, B. The Biasing Health Halos of Fast-Food Restaurant Health Claims: Lower Calorie Estimates and Higher Side-Dish Consumption Intentions. J. Consum. Res. 2007, 34, 301-314. [CrossRef]

16. Kim, M.H.; Yang, J.H. Effects of nutrition claims on consumers' health believes, brand attitudes and perceptions of disease-related risks. J. Consum. Stud. 2010, 21, 53-81.

17. Mishra, A.; Mishra, H. The Influence of Price Discount versus Bonus Pack on the Preference for Virtue and Vice Foods. J. Mark. Res. 2011, 48, 196-206. [CrossRef]

18. Jiang, Y.; Lei, J. The effect of food toppings on calorie estimation and consumption. J. Consum. Psychol. 2013, 24, 63-69. [CrossRef]

19. Kim, S.Y.; Lee, J.H. Effect of nutrition labeling use on consumers' food choices. J. Consum. Stud. 2010, 21, 107-128.

20. Trope, Y.; Fishbach, A. Counteractive self-control in overcoming temptation. J. Pers. Soc. Psychol. 2000, 79, 493-506. [CrossRef]

21. Hwang, J.J. How Does Nutritional Information about Fast Food Menu Items Influence Consumer Choice Behavior according to their Health Consciousness and Nutritional Knowledge? Korean J. Hosp. Tour. 2012, 21, 93-112. Available online: http: / / www.dbpia.co.kr/journal/articleDetail?nodeId=NODE02484488 (accessed on 11 May 2021).

22. Sah, J.Y.; Yeo, J.S. Efficacy and Accuracy of Consumer Responses for Four Different Nutrition Label Formats. Consum. Policy Educ. Rev. 2014, 10, 217-245. [CrossRef]

23. Richardson, P.S.; Dick, A.S.; Jain, A.K. Extrinsic and Intrinsic Cue Effects on Perceptions of Store Brand Quality. J. Mark. 1994, 58, 28-36. [CrossRef]

24. Song, M.R.; Im, M.J. The Halo Effect of Additive-Free Claims in Food and Consumer Goods. Korean J. Consum. Advert. Psychol. 2016, 17, 199-222. [CrossRef]

25. Marozzo, V.; Raimondo, M.A.; Miceli, G.; Scopelliti, I. Effects of au naturel packaging colors on willingness to pay for healthy food. Psychol. Mark. 2019, 37, 913-927. [CrossRef]

26. Donato, C.; Barone, A.M.; Romani, S. The Satiating Power of Sustainability: The Effect of Package Sustainability on Perceived Satiation of Healthy Food. Br. Food J. 2021, 123, 162-177. Available online: https://www.emerald.com/insight/0007-070X.htm (accessed on 22 July 2021). [CrossRef]

27. Gao, Y.; Mattila, A.S. The impact of stereotyping on consumers' food choices. J. Bus. Res. 2017, 81, 80-85. [CrossRef]

28. Lascu, D.-N. Consumer Guilt: Examining the Potential of a New Marketing Construct. Adv. Consum. Res. 1991, 18, 290-295. Available online: https:/ / www.acrwebsite.org/volumes/7175/volumes/v18/NA-18 (accessed on 23 July 2021).

29. Hochwarter, W.A.; Perrewé, P.L.; Meurs, J.A.; Kacmar, C. The interactive effects of work-induced guilt and ability to manage resources on job and life satisfaction. J. Occup. Health Psychol. 2007, 12, 125-135. [CrossRef]

30. Kim, S.H. An study on influence of salespersons' guilt and shame in sales performance failure -Individualism and Collectivism. J. Mark. Manag. Res. 2014, 19, 37-64.

31. Kivetz, R.; Simonson, I. Earning the Right to Indulge: Effort as a Determinant of Customer Preferences toward Frequency Program Rewards. J. Mark. Res. 2002, 39, 155-170. [CrossRef]

32. Keinan, A.; Kivetz, R. Remedying Hyperopia: The Effects of Self-Control Regret on Consumer Behavior. J. Mark. Res. 2008, 45, 676-689. [CrossRef]

33. Xu, J.; Schwarz, N. Do We Really Need a Reason to Indulge? J. Mark. Res. 2009, 46, 25-36. [CrossRef]

34. Park, S.H.; Lim, G.Y.; Sohn, Y.W. The effect of opportunity cost consideration on willingness to purchase: The mediating role of indulgence guilt. Korean J. Consum. Advert. Psychol. 2013, 14, 1-23. [CrossRef]

35. Dhar, R.; Wertenbroch, K. Consumer Choice between Hedonic and Utilitarian Goods. J. Mark. Res. 2000, 37, 60-71. [CrossRef]

36. Prelec, D.; Loewenstein, G. The Red and the Black: Mental Accounting of Savings and Debt. Mark. Sci. 1998, 17, 4-28. [CrossRef]

37. Strahilevitz, M.; Myers, J.G. Donations to Charity as Purchase Incentives: How Well They Work May Depend on What You Are Trying to Sell. J. Consum. Res. 1998, 24, 434-446. [CrossRef] 
38. Hagtvedt, H.; Patrick, V.M. Gilt and Guilt: Should Luxury and Charity Partner at the Point of Sale? J. Retail. 2016, 92, 56-64. [CrossRef]

39. Cheon, H.S.; Kim, D.W. Related to Smoking Exposure, the Influences of Tobacco Companies' Anti-Smoking Advertisements on Attitude toward Advertising, Smoking Cessation Intention \& the Corporate Images Upon to the Message Types. Korean J. Advert. 2010, 21, 27-55. Available online: http:/ / scholarworks.bwise.kr/ssu/handle/2018.sw.ssu/15501 (accessed on 10 August 2021).

40. Sundar, A.; Cao, E.; Wu, R.; Kardes, F.R. Is unnatural unhealthy? Think about it: Overcoming negative halo effects from food labels. Psychol. Mark. 2021, 38, 1280-1292. [CrossRef]

41. Ni Mhurchu, C.; Gorton, D. Nutrition labels and claims in New Zealand and Australia: A review of use and understanding. Aust. N. Zealand J. Public Health 2007, 31, 105-112. [CrossRef]

42. Roe, B.; Levy, A.S.; Derby, B.M. The Impact of Health Claims on Consumer Search and Product Evaluation Outcomes: Results from FDA Experimental Data. J. Public Policy Mark. 1999, 18, 89-105. [CrossRef]

43. Garretson, J.A.; Burton, S. Effects of Nutrition Facts Panel Values, Nutrition Claims, and Health Claims on Consumer Attitudes, Perceptions of Disease-Related Risks, and Trust. J. Public Policy Mark. 2000, 19, 213-227. [CrossRef]

44. Laran, J.; Janiszewski, C. Work or Fun? How Task Construal and Completion Influence Regulatory Behavior. J. Consum. Res. 2011, 37, 967-983. [CrossRef]

45. Shafir, E.; Simonson, I.; Tversky, A. Reason-based choice. Cognition 1993, 49, 11-36. [CrossRef]

46. Tversky, A.; Sattath, S.; Slovic, P. Contingent weighting in judgment and choice. Psychol. Rev. 1988, 95, 371-384. [CrossRef]

47. Shao, A.; Li, H. How do utilitarian versus hedonic products influence choice preferences: Mediating effect of social comparison. Psychol. Mark. 2021, 38, 1250-1261. [CrossRef]

48. Roy, R.; Soo, D.; Conroy, D.; Wall, C.R.; Swinburn, B. Exploring University Food Environment and On-Campus Food Purchasing Behaviors, Preferences, and Opinions. J. Nutr. Educ. Behav. 2019, 51, 865-875. [CrossRef]

49. Park, S.H. Guilt effects on consumer choice between hedonic and utilitarian products. Korean J. Mark. 2005, 20, 21-44.

50. Zhong, C.-B.; Liljenquist, K. Washing Away Your Sins: Threatened Morality and Physical Cleansing. Science 2006, 313, 1451-1452. [CrossRef]

51. Tversky, A.; Kahneman, D. Loss Aversion in Riskless Choice: A Reference-Dependent Model. Q. J. Econ. 1991, 106, 1039-1061. [CrossRef]

52. Taylor, J.W. The Role of Risk in Consumer Behavior. J. Mark. 1974, 38, 54-60. [CrossRef]

53. Slovic, P.; Peters, E. Risk Perception and Affect. Curr. Dir. Psychol. Sci. 2006, 15, 322-325. [CrossRef]

54. Kemp, E.; Bui, M.; Porter, I.M. Preparing for a crisis: Examining the influence of fear and anxiety on consumption and compliance. J. Consum. Mark. 2021, 38, 282-292. [CrossRef]

55. You, M.S.; Ju, Y.K. Food risk perception in South Korea: The role of affect, trust, and media use. Korean J. Journal. Commun. Stud. 2013, 57, 211-233.

56. Sparks, P.; Shepherd, R. Public perceptions of the potential hazards associated with food production and food consumption: An empirical study. Risk Anal. 1994, 14, 799-806. [CrossRef]

57. Jun, S.M. Effects of Health-Related Food Labeling on Quality Assessment Before Purchase, Attitudes towards Using and Purchasing Products, and Purchase Intentions Based on the Theory of Planned Behavior. J. Consum. Cult. 2012, 15, 67-90. [CrossRef]

58. Park, S.J. The Influence of Product Assortment Size and Bundle Discount on Items Selection of a Bundle. Korean Manag. Rev. 2012, 41, 259-278. Available online: http:/ / www.dbpia.co.kr/journal/articleDetail?nodeId=NODE06079899 (accessed on 22 July 2021).

59. Ketron, S.; Naletelich, K.; Migliorati, S. Representational versus abstract imagery: Effects on purchase intentions between vice and virtue foods. J. Bus. Res. 2020, 125, 52-62. [CrossRef] 